\title{
A moisture-absorbing and abrasion-resistant transparent coating on polystyrene
}

\author{
Svenja Grube, Konstantin Siegmann, \\ Martina Hirayama
}

(C) The Author(s) 2015. This article is published with open access at Springerlink.com

\begin{abstract}
A common phenomenon concerning cold surfaces which are subjected to a warmer, more humid atmosphere is condensation in the form of water droplets (fogging) or even ice crystals (icing). Thus, a previously transparent object becomes opaque because light is scattered by the droplets or crystals. This may impair the usability of that object. We developed an anti-fogging/icing coating which overcomes the problem of fogging and icing by being able to absorb the condensing water and preventing it from crystallizing. The coating consists of poly(1-vinyl-2-pyrrolidone) (PVP) crosslinked by UV light using hydrogen peroxide $\left(\mathrm{H}_{2} \mathrm{O}_{2}\right)$. Benzophenone (BP) is used to attach PVP to the surface of the polystyrene (PS) substrate. At temperatures as low as $-60^{\circ} \mathrm{C}$, the PVP coating can absorb up to $70 \mathrm{wt} \%$ of water and still inhibit its crystallization. However, at surface temperatures of around $-18^{\circ} \mathrm{C}$, opacity is only observable at $150 \mathrm{wt} \%$ of absorbed water and higher. An increasing coating thickness as well as a decreasing crosslink density improves the anti-fogging/icing effect because the coating can absorb more water. The abrasion resistance of the coating is impaired by a decreasing crosslink density.
\end{abstract}

Keywords Anti-icing, Poly(1-vinyl-2-pyrrolidone), Swelling, Abrasion, UV crosslinking

S. Grube, K. Siegmann, M. Hirayama ( $\square)$

Institute of Materials and Process Engineering, School of

Engineering, Zurich University of Applied Sciences,

Technikumstrasse 9, P.O. Box 8401, Winterthur,

Switzerland

e-mail: martina.hirayama@zhaw.ch

S. Grube

e-mail: svenja.grube@zhaw.ch

K. Siegmann

e-mail: konstantin.siegmann@zhaw.ch

\section{Introduction}

Water is ever-present, surrounding us in various states, for instance as atmospheric humidity, rain, snow, or supercooled droplets. These types of water may cause problems for indoor as well as outdoor applications. Supercooled droplets in the atmosphere, for example, can result in ice accretion on available surfaces. The function of applications like wind turbines, power lines, or aircraft can thereby be seriously impaired and counter measures like active or passive de-icing or even anti-icing need to be taken. ${ }^{1-4}$

Atmospheric humidity can entail condensation when combined with a cold surface. More precisely, if the temperature of said surface is lower than the dew point of the humid air, condensation onto that surface will occur. ${ }^{5}$ Light is scattered comparatively strongly because of the high surface area and rather high contact angle of the droplets that form. ${ }^{6}$ Formerly clear materials thus become opaque. If the temperature of the surface is even below the freezing point of water, ice crystals will form on the surface, which makes it difficult to see through such materials.

Whether this is a problem or not depends on the usage of the particular surface. There can be aesthetic reasons why condensation is undesirable, but there can also be safety or performance-relevant issues. There are applications where transparency is crucial (e.g., mirrors, solar panels, windows, glasses/goggles, visors) or where the function is impaired by condensation (e.g., packaging, electronics, heat exchangers).

The aim of this study was to prevent fogging and, especially in cold environments, the freezing of condensed water. The specific area of application that we are concerned with is transparent drawers in freezers. Upon opening the door of a freezer, it should be possible to see what is stored in the drawers. Because of air moisture, the surfaces of the drawers often fog, meaning that the contents can no longer be identified. The coating 
described here was made to prevent fogging in a cold environment, thus potentially reducing the period of time for which the freezer has to stay open before the product required is found.

In order to prevent a surface from fogging, there are several options. One is to render the surface superhydrophobic, ${ }^{7}$ so that all droplets that might form roll off the surface immediately. This, however, is mainly applicable in an environment where the condensed water does not freeze. ${ }^{9}$ The approach we took was hydrophilization of the surface. Hydrophilization can, for example, be achieved by plasma treatment, ${ }^{10-12}$ or coating with inorganic $\left(\mathrm{TiO}_{2}, \mathrm{ZnO}\right)^{13-15}$ or organic substances (hydrophilic polymers). ${ }^{16,17}$

One feature of a hydrophilic surface is a low contact angle of water $\left(<90^{\circ}\right)$. Thus, if water droplets condense on such a surface, they spread into each other and form one film. This film is transparent, because it scatters light only to a small extent, which is comparable to the transparent material itself and invisible to the human eye. However, this film is still able to freeze and form ice crystals that scatter light. Hydrophilicity can, as in our case, also be created using a polymeric coating which forms a transparent hydrogel by absorbing water. A further advantage of this type of coating is that the absorbed water, to a certain extent, will not freeze, even if the temperature is considerably lower than the freezing point of water. This kind of water is conveniently called "non-freezing water". ${ }^{18-20}$ The effect is achieved by interactions between the hydrophilic polymer chains and the water molecules. Hence, for the application of keeping drawers in a freezer transparent upon opening the door, this kind of surface treatment is, in our view, the preferred method.

The substrate material we used was polystyrene (PS). PS is not hydrophilic; therefore, to make a hydrophilic coating adhere to it, it has to be pretreated. Plasma activation renders the PS surface hydrophilic, so that the coating solution will wet it. The hydrophilic polymer we used was poly(1-vinyl-2-pyrrolidone) (PVP). The relative inertness of PS makes it difficult to covalently bind the hydrophilic PVP onto the PS surface. This study shows how to solve the problem of making PVP adhere to the PS surface and also how to render the swollen and thus soft PVP coating abrasionresistant. Furthermore, it extensively deals with elucidating the anti-fog and anti-freeze effect of the coating.

\section{Materials and methods}

Polystyrene (General Purpose PS), which was used for the substrate, was injection-molded into flat plates with a thickness of $2-3 \mathrm{~mm}$. PVP (K 90, M $\approx 360,000 \mathrm{~g} / \mathrm{mol}$ ), hydrogen peroxide $\left(\mathrm{H}_{2} \mathrm{O}_{2}, 30 \mathrm{wt} \%\right.$ solution in water, Perdrogen) and benzophenone (BP, purity of $99 \%$ ) were purchased from Sigma-Aldrich. Ethanol (non-denatured) was purchased from Alcosuisse. The chemicals were used as received.
The same coating solution was prepared for all experiments. Then, $2 \mathrm{~g}$ of PVP was dissolved in $30 \mathrm{~mL}$ of ethanol. Afterward, $3 \mathrm{~mL}$ of $\mathrm{H}_{2} \mathrm{O}_{2}$ and $50 \mathrm{mg}$ ( $2.5 \mathrm{wt} \%$ based on the amount of PVP) of BP were added and dissolved. The solution was stored in a refrigerator at $2-8^{\circ} \mathrm{C}$ in the dark.

\section{Coating process}

The cleaned PS plates were first activated with argon plasma (Diener Nano, 0.3 mbar argon pressure, 100\% generator power, $2 \mathrm{~min}$ ). The activation provides improved wetting of the coating solution on the PS plates. Wherever possible, directly after, the plates were coated with the coating solution by dipping. The coated samples were then allowed to dry. After drying, the samples were subjected to UV curing to crosslink the PVP coating. The UV lamp was a product of the Dr. Hönle AG (low-pressure Fe-doped mercury-vapor lamp, power: $100 \mathrm{~W} / \mathrm{cm}$, irradiance: $200 \mathrm{~mW} / \mathrm{cm}^{2}$, $20 \mathrm{~cm}$ distance between lamp and sample). The main emission peak of this lamp is at $366 \mathrm{~nm}$ with another relatively prominent peak at $254 \mathrm{~nm}$. The coating was irradiated for $6 \mathrm{~min}$. For some experiments, the irradiation time was varied, as indicated in the relevant section.

\section{Characterization of the coatings}

Different analytical methods were used to characterize the coating and its properties.

The coating thickness of different samples was measured by two methods, namely SEM-measurements (Zeiss Supra 40VP) of the crosscut of the coatings on glass slides and eddy current measurements (Fischer Dualscope MP40) of the coatings on an aluminum alloy as a substrate. It was shown that the results of both methods were within each other's standard deviation and could thus be considered indistinguishable. The more convenient eddy current method was used for further thickness measurements.

Contact angle measurements were carried out to show that the anti-fogging mechanism functions via the absorption of water into the coating. We used the Krüss DSA 100 Drop Shape Analysis System with the sessile drop technique. The liquid was Milli-Q water at a droplet volume of $5 \mu \mathrm{L}$. The droplet was placed on the surface of the coating and monitored for $10 \mathrm{~min}$ to detect changes in contact angle, drop shape, and size. All measurements were carried out on the same day under the same environmental conditions, at room temperature and ambient humidity.

Dynamic scanning calorimetry (DSC) measurements (Mettler Toledo DSC $822^{\mathrm{e}}$ ) were carried out to examine the freezing behavior of water absorbed within the PVP coating. The coating was prepared as explained above; however, glass slides were used as a substrate so that the coating could be detached easily 
by brief swelling in water. The dried PVP samples were then placed into a humid atmosphere $(100 \%$ rh at 22 $24^{\circ} \mathrm{C}$ ) for different periods of time to obtain various degrees of swelling. After weighing, they were put into hermetically sealed aluminum crucibles and cooled from 25 to $-60^{\circ} \mathrm{C}$ before being heated from -60 to $25^{\circ} \mathrm{C}$, twice each at a rate of $10^{\circ} \mathrm{C} / \mathrm{min}$. The second heating curve was used for analysis. The samples were weighed before and after the measurements to make sure the absorbed water did not evaporate during the experiment.

To determine the influence of the coating thickness of the PVP coating on the anti-fog performance under real conditions, some samples were prepared at a range of coating thicknesses and weighed in the dry, nonswollen state. The samples were placed inside a freezer $\left(-18^{\circ} \mathrm{C}\right)$ and cooled. They were then taken out of the freezer and weighed after $30 \mathrm{~s}$ of being allowed to absorb humidity from the surrounding atmosphere. The humidity was $40 \pm 10 \%$ rh at room temperature $\left(22 \pm 1{ }^{\circ} \mathrm{C}\right)$. Then, they were put into the freezer again for $30 \mathrm{~min}$ and removed again. Overall, this process was repeated four times. Afterward, the samples were kept in the freezer for two hours to properly cool. They were then subjected to a higher humidity of $89 \pm 2 \%$ rh at $25 \pm 1^{\circ} \mathrm{C}$ and weighed. The values were used to determine the degree of swelling.

Another water absorption test was performed by weighing the samples in the dry, non-swollen state, immersing them in a water bath for $30 \mathrm{~min}$ at room temperature $\left(22 \pm 1^{\circ} \mathrm{C}\right)$ and afterward weighing them again, after getting rid of superficial, unabsorbed water. As a result, the equilibrium degree of swelling of the coatings was determined at different coating thicknesses as well as different irradiation times. In these measurements, standard deviations of up to $15 \%$ were observed.

Abrasion testing was carried out with the Elcometer 1720 Abrasion Tester. This test made it possible to compare the abrasion resistance of different samples. It was simultaneously used to simulate the cleaning process which may become necessary in real life usage of the drawers and to cause considerable mechanical strain. The samples were weighed before the abrasion test. For the actual testing, a sponge (Scotch-Brite, soft and rough side, non-scratching) was moved across the sample by an arm which moves back and forth in one cycle. The sponge had an area of about $35 \mathrm{~cm}^{2}$ and was pressed onto the samples with a weight of about $500 \mathrm{~g}$, resulting in a pressure of about $1.3 \mathrm{kPa}$. Before the procedure, a $1 \mathrm{wt} \%$ solution of a standard detergent in water was poured over the samples so that they were covered and thus swollen. The sponge was wetted and the experiment was carried out with the soft side of the sponge. The arm moved at a rate of 60 cycles per minute for 90 cycles in total (1.5 min). Afterward, the samples were rinsed with deionized water and left to dry. After weighing and judging them optically as well as microscopically (Zeiss Axio Imager.A1 m), the same procedure was carried out with the rough side of the sponge on the same samples. In these measurements, standard deviations of up to $15 \%$ were observed.

A climate chamber equipped with a cooling stage (Linkam LNP 94/2, TMS 94, LTS 350) was used to determine differences in the crystallization behavior of water from humid air on cooled samples equipped with the anti-fogging coating. The cooling stage is enclosed in a sealed chamber with a window on top. It can be used to cool down samples the size of an object slide with liquid nitrogen which circulates in the stage, on top of which the sample is placed. Temperatures down to $-196^{\circ} \mathrm{C}$ are accessible. Humid air can be inserted into the chamber through an air duct and streamed across the cooled sample. By placing the chamber under a microscope, changes to the sample can be monitored. For our study, stage temperatures between -20 and $-50^{\circ} \mathrm{C}$ were used. The humid air was streamed across the sample at a rate of $1 \mathrm{~L} / \mathrm{min}$ at room temperature $\left(24 \pm 1^{\circ} \mathrm{C}\right)$ and a humidity of $50 \% \mathrm{rh}$.

\section{Results and discussion}

There are two main requirements for the coating presented here. The purpose of the coating is to prevent opacity because of condensation and freezing of water on the surface of the freezer drawers. Thus, it has to be effective for preventing fogging as well as icing. Additionally, it has to be resistant to abrasion, to a certain extent, as it might be necessary to clean the drawers mechanically in everyday life. Both of these properties were investigated to develop the coating.

\section{Coating mechanism}

The coating chosen for our application was crosslinked PVP applied to a PS substrate. For this coating to be abrasion-resistant, the crosslink density needs to be sufficiently high, ${ }^{21,22}$ especially at the surface of the coating. However, a homogeneous crosslink distribution is favorable; otherwise, swelling of the coating can form patterns ${ }^{23-25}$ on the surface which lead to scattering, resulting in opacity.

PVP in an aqueous solution is known to crosslink when irradiated with UV light. Adding $\mathrm{H}_{2} \mathrm{O}_{2}$ increases the rate of that reaction and makes it more efficient. ${ }^{26}$ Under UV light, $\mathrm{H}_{2} \mathrm{O}_{2}$ decomposes into two hydroxyl radicals which facilitate the crosslinking. For the PVP coating to sufficiently adhere to the PS-surface, there need to be interactions between the surface and the coating, preferably covalent bonds. These covalent bonds were created by the use of BP. BP is a type-IIphotoinitiator, which can abstract $\mathrm{H}$-atoms and leave radicals on the PS surface ${ }^{27}$ (Fig. 1) when irradiated at an appropriate wavelength (see Fig. 3). These reactive sites can then combine with radicals on the PVP chain created by the reaction with the above-mentioned hydroxyl radicals. Figure 2 schematically shows how 
this crosslinking could occur. ${ }^{28}$ Prior plasma activation significantly increases the adhesion of the coating to PS, because the wetting of the surface by the coating solution is distinctly improved.

Figure 3 shows the absorption spectra (Perkin Elmer Lambda 2) of BP, $\mathrm{H}_{2} \mathrm{O}_{2}$, and PVP and also the emission spectrum of the UV lamp (gray, vertical lines). At $366 \mathrm{~nm}, \mathrm{BP}$ shows some absorption but $\mathrm{H}_{2} \mathrm{O}_{2}$ only absorbs negligibly. The lower wavelengths of the emission spectrum of the UV lamp, especially around $254 \mathrm{~nm}$, are thus mainly responsible for the homolysis of $\mathrm{H}_{2} \mathrm{O}_{2}$ because it absorbs much more strongly in that region. BP absorbs more efficiently as well; however, only the $n \pi^{*}$-transition at around $340 \mathrm{~nm}$ enables it to carry out the hydrogen abstraction reaction necessary to bind PVP to the PS surface ${ }^{29}$ (see Fig. 1).

Figure 4 shows the absorption spectra of the dry, not-yet-crosslinked coating before radiation curing (straight line; consisting of PVP, $\mathrm{H}_{2} \mathrm{O}_{2}, \mathrm{BP}$ ) and of the crosslinked coating after radiation curing (dashed line). The coating, exhibiting a thickness of about $5 \mu \mathrm{m}$, is not applied to the usual PS substrate but to a

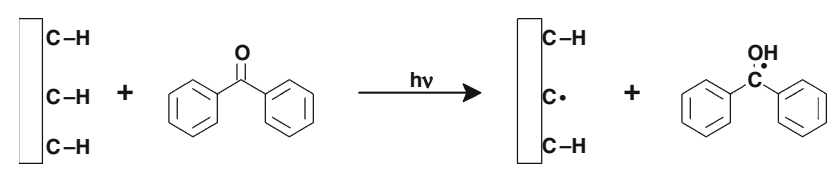

Fig. 1: Schematic illustration of BP abstracting a hydrogen atom from a PS surface under the influence of UV light quartz glass slide. As a result, the absorption of the substrate does not interfere with the absorption of the coating because the absorption of quartz glass is negligible in the observed region, whereas PS strongly absorbs at wavelengths lower than approximately $300 \mathrm{~nm}$. The emission spectrum of the UV lamp is illustrated as gray, vertical lines. The absorption band

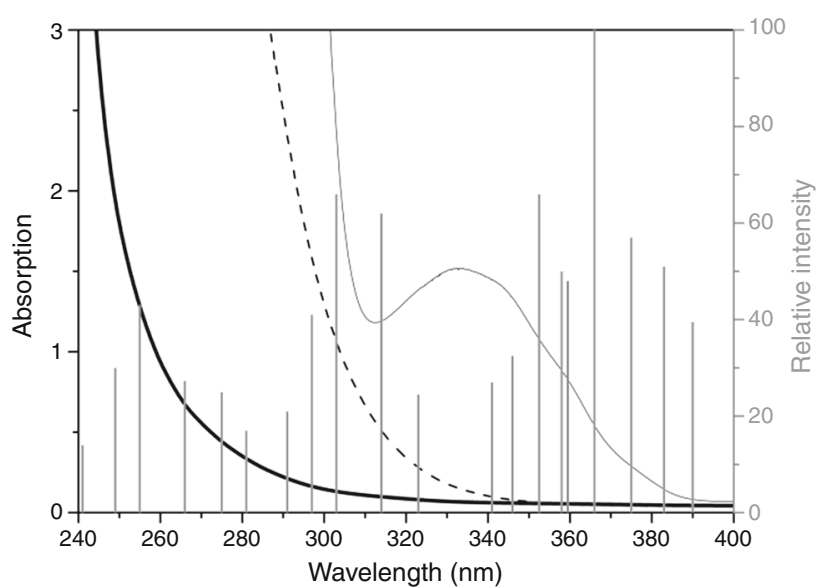

Fig. 3: UV-Vis spectra of PVP (thick line, left y-axis), $\mathrm{H}_{2} \mathrm{O}_{2}$ (dashed line, left $y$-axis), and benzophenone (thin line, left $y$-axis) each dissolved in ethanol at the actual concentration of the coating solution; the gray vertical lines (right yaxis) depict the emission spectrum of the Fe-doped mercury vapor lamp
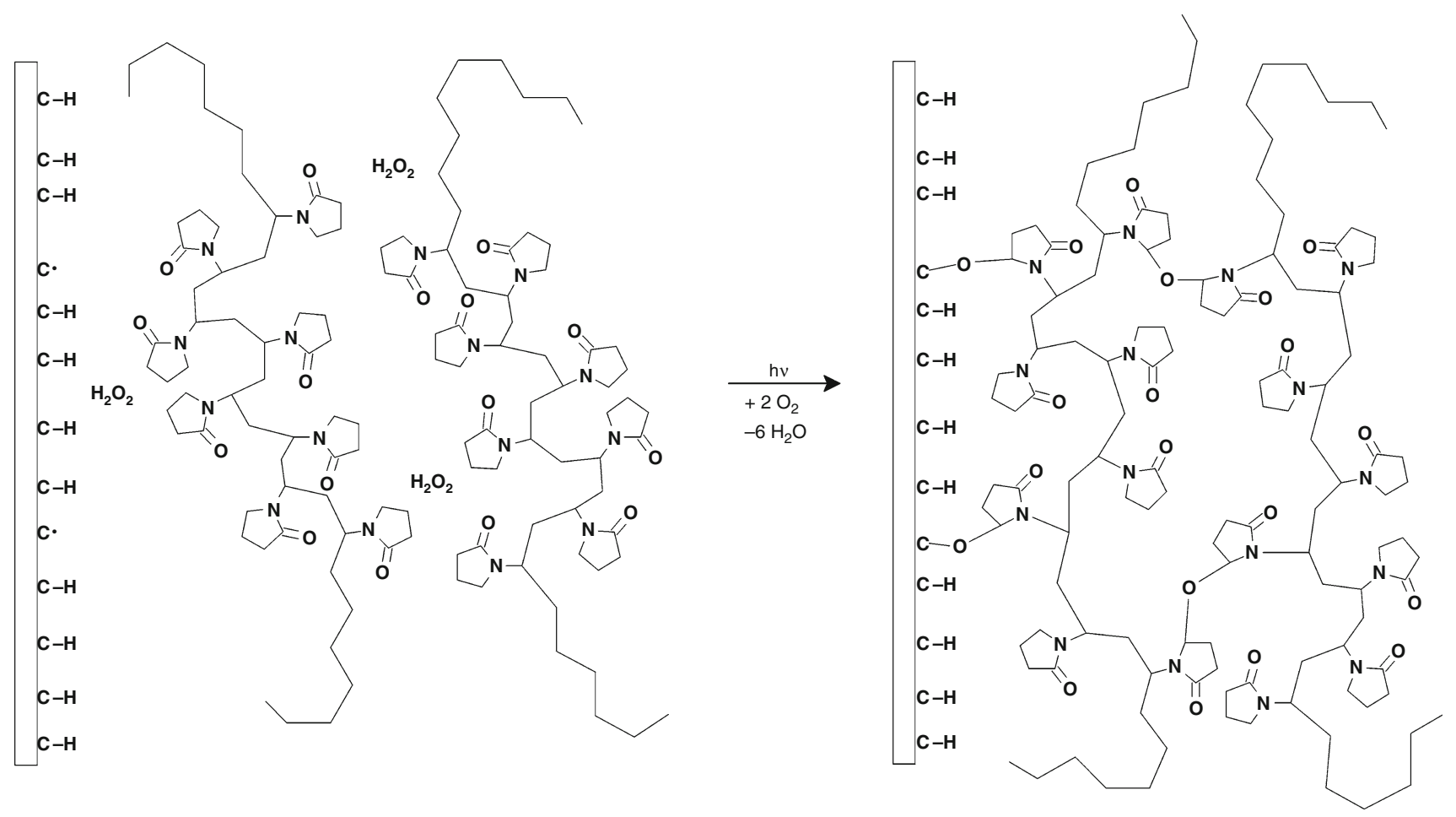

Fig. 2: Schematic illustration of the crosslinking reaction of PVP using $\mathrm{H}_{2} \mathrm{O}_{2}$ and UV light 


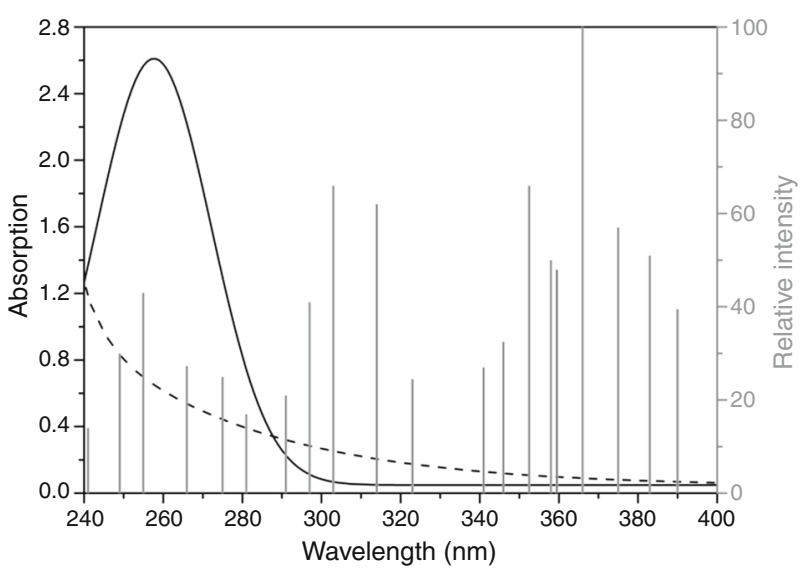

Fig. 4: UV-Vis spectra of a 5- $\mu \mathrm{m}$ thick PVP coating applied to a quartz glass slide whose absorption is negligible in this wavelength range; straight line: not-yet-crosslinked coating before UV irradiation (line smoothed, left y-axis), dashed line: crosslinked coating after $6 \mathrm{~min}$ UV radiation curing (left y-axis); the gray vertical lines (right y-axis) depict the emission spectrum of the Fe-doped mercury vapor lamp

before irradiation mainly stems from the components $\mathrm{BP}$ and $\mathrm{H}_{2} \mathrm{O}_{2}$ (compare Fig. 3). At a wavelength of around $340 \mathrm{~nm}$, the $n \pi^{*}$-transition of $\mathrm{BP}$ is not visible because of its small extent (absorption of about 0.02), but it is enough to result in a reasonably strong adhesion of the coating to PS. Absorption primarily takes place between 240 and $280 \mathrm{~nm}$ where the UV lamp still has some minor emission peaks, generating hydroxyl radicals from $\mathrm{H}_{2} \mathrm{O}_{2}$. After the radiation curing, the absorption band disappears, indicating that the main part of $\mathrm{H}_{2} \mathrm{O}_{2}$ and $\mathrm{BP}$ has reacted.

\section{Absorption and swelling}

Since freezer drawers are cold, usually about $-18^{\circ} \mathrm{C}$, water from the surrounding atmosphere will condense onto them as droplets and may even freeze, forming ice crystals. This process creates opacity and it becomes difficult to see through the normally transparent drawers. To avoid this effect, we developed this PVP coating, which functions by absorbing the condensed water, thus preventing it from freezing.

The relative amount of absorbed water can be quantified by the degree of swelling, $q$, of the coating. In this case, the mass-based degree of swelling, $q_{\mathrm{w}}$, is used as shown in Eq. 1. The mass of the swollen coating, $m_{\text {swollen }}$, is simply divided by the mass of the dry coating, $m_{\mathrm{dry}}$, with the mass of the absorbed water being $m_{\text {water }}$.

$q_{\mathrm{w}}=\frac{m_{\mathrm{swollen}}}{m_{\mathrm{dry}}}=\frac{m_{\mathrm{water}}+m_{\mathrm{dry}}}{m_{\mathrm{dry}}}$

The absorption process can be verified by studying the variation of the contact angle of a water droplet on the

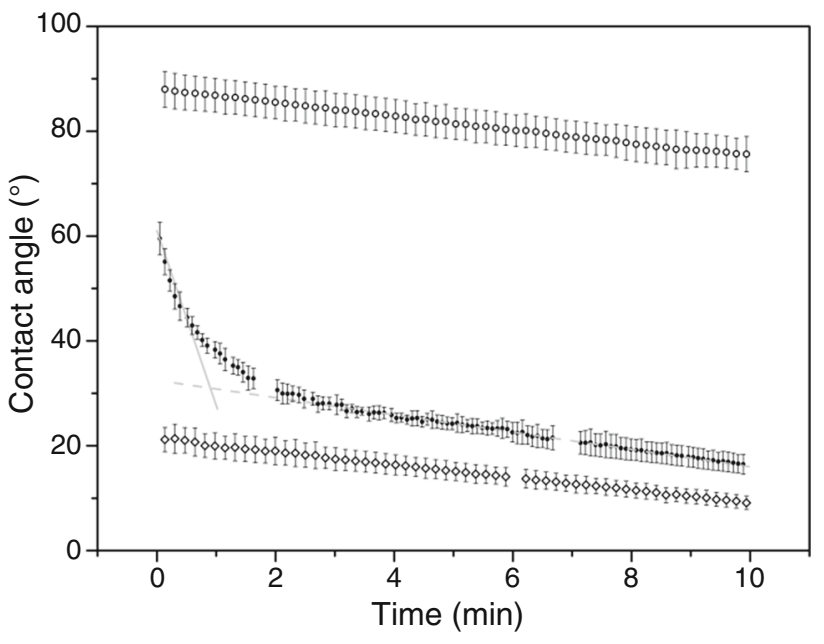

Fig. 5: Change in the contact angle of a water droplet $(5 \mu \mathrm{L})$ with time on different samples; open circles: untreated PS surface, decrease: $-1.3 \% \mathrm{~min}$; open diamonds: Ar plasma-activated PS surface, decrease: $-1.2 \%$ min; black dots: crosslinked PVP coating on PS; gray solid line: initial decrease $(-33.3 \% \mathrm{~min})$ caused by absorption of the water droplet into the coating; gray dashed line: longterm decrease $(-1.7 \% \mathrm{~min})$ caused by evaporation of water

coating with time. In Fig. 5, the contact angle of water on the PVP coating is compared to that on an untreated PS plate as well as on an Ar plasmaactivated PS plate. The PS plates are incapable of absorbing observable amounts of water, so the contact angle should behave differently from that of the PVP coating.

The contact angle on the uncoated PS plates decreases linearly with time, in both cases exhibiting an almost identical slope. This decrease can be explained by the evaporation of water. The contact radius of the droplet on the PS plate remains unchanged during the process, so that the contact angle automatically decreases with time when water evaporates. ${ }^{30-32}$

The behavior of the PVP coating is different. In the first $30 \mathrm{~s}$, there is a sharp decline in the contact angle which then levels off to a linear decrease with a slope similar to that of the measurements on PS. In the beginning, the contact angle decreases too fast to solely be attributed to evaporation. The decrease can be explained with absorption of the water droplet by the coating. The shrinkage of the droplet can even be seen with the naked eye. However, the coating was not able to absorb the whole droplet, so the remainder could still be observed. At longer times, it exhibited a slow and linear decrease in contact angle, with a slope just slightly higher than that for the PS plates. This longterm decrease is, therefore, at least partly caused by water evaporation. The somewhat higher slope indicates that it is not only due to evaporation; absorption still plays a minor role. Measurements on samples with 
different coating thicknesses showed no correlation between coating thickness and contact angle.

\section{Non-freezing water}

It has been shown that the PVP coating can absorb water, which is part of the reason for its use as an antifogging agent. However, the area of application worked on here not only has to deal with fogging by liquid water droplets but also by ice crystals. Figure 6 shows four samples. Those on the left (a to c) are coated with different coating thicknesses from 13 to $1 \mu \mathrm{m}$ and the one on the right (d) is not coated. Beforehand, these samples were placed in a freezer (ca. $-18^{\circ} \mathrm{C}$ ) overnight. Then, they were taken out and directly photographed. The two plates on the left $(a, b)$ have a higher coating thickness and do not exhibit any fogging. Sample $\mathrm{c}$ has a lower coating thickness and shows fogging. The uncoated PS plate on the right (d) shows even stronger fogging owing to the formation of ice crystals.

The reason why the absorbed water does not crystallize can be explained by its interactions with the hydrophilic PVP network. Up to a certain degree of swelling, the absorbed water is in close contact with PVP, exhibiting rather strong interactions. A phase transition cannot be observed by DSC when the sample is cooled, even to very low temperatures compared to the usual freezing point of free water. Accordingly, water in this state is called "non-freezing water". ${ }^{18-20}$ Ping et al. ${ }^{19}$ determined this threshold to be at about four molecules of water per pyrrolidone moiety. Considering the molecular weight of the monomer unit of PVP $(111 \mathrm{~g} / \mathrm{mol})$ and water $(18 \mathrm{~g} / \mathrm{mol})$, this corresponds to a degree of swelling of $q_{\mathrm{w}} \approx 1.7$. If the amount of water within the hydrogel increases above four molecules per pyrrolidone moiety, not all of it makes contact with PVP as closely as before and it is surrounded much more by other water molecules. It now exhibits crystallization if cooled; however, it is supercooled significantly stronger than free water. Water in this state is called "freezing bound water." Non-freezing water and freezing bound water together are called "bound water." Water that is absorbed within a hydrophilic polymer but exhibits a melting temperature and enthalpy of fusion that is undistinguishable from free water is called "freezing water" and appears at even higher degrees of swelling.

In order to examine our coating with regard to bound water, DSC measurements of swollen PVP were performed. Comparative measurements of pure water were also run.

Figure 7 shows comparisons between DSC heating curves of pure water and the swollen PVP coating. The absolute amount of water of the two curves in the left as well as the right graph is comparable; however, the DSC curves show quite different behavior. On the left hand side, the pure water $(1.1 \mathrm{mg})$ shows a melting peak. A similar amount of water $(1.4 \mathrm{mg})$ absorbed within the crosslinked PVP does not show any signs of melting. Only the glass transition of PVP at about $7^{\circ} \mathrm{C}$, softened by water, can be detected. The water absorbed within PVP at this degree of swelling can certainly be termed non-freezing water. The graph on the right hand side depicts samples with a higher amount of water and, more importantly, a higher degree of swelling. The absorbed water $(4.32 \mathrm{mg}$ ) shows a melting peak, but the enthalpy of fusion (area under the curve) is noticeably smaller than that of the same amount of pure water $(4.3 \mathrm{mg})$. Moreover, it starts to melt at temperatures below $0^{\circ} \mathrm{C}$. Here, part of the absorbed water falls into the category of freezing bound water.

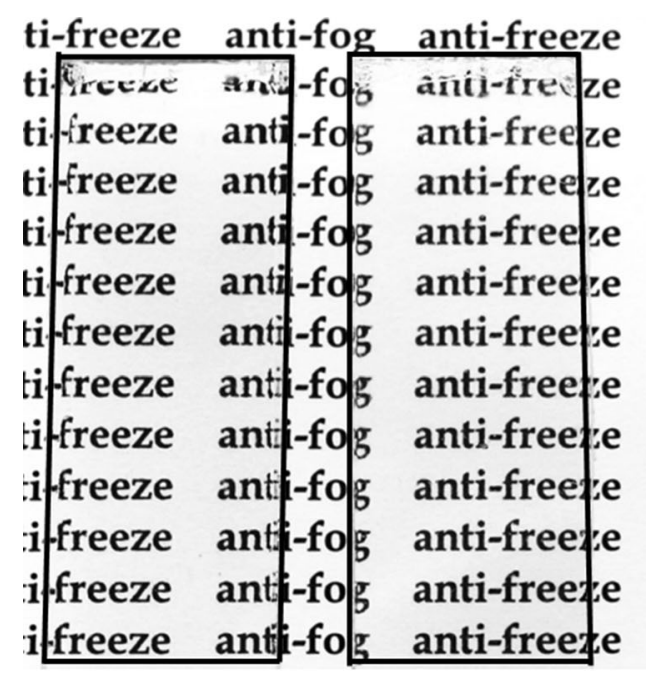

(a)

(b)

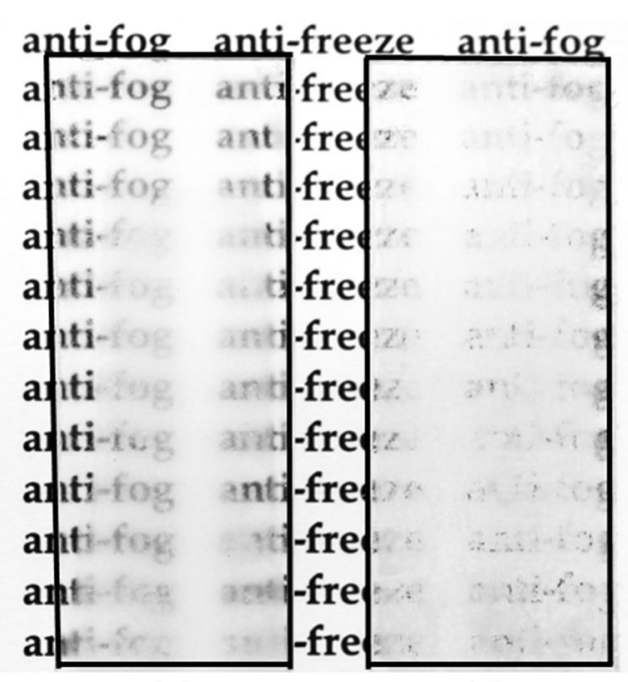

(c) (d)

Fig. 6: Coated and uncoated PS plates directly after taking them out of the freezer $\left(-18^{\circ} \mathrm{C}\right)$; (a) coating thickness $13 \mu \mathrm{m}$, no fogging; (b) coating thickness $6 \mu \mathrm{m}$, no fogging; (c) coating thickness $1 \mu \mathrm{m}$, fogging; (d) blank PS, strong fogging 



Fig. 7: DSC heating curves comparing pure water and water absorbed in the PVP coating, exo up; left hand side: dashed line: $1.1 \mathrm{mg}$ pure water $\left(\Delta H_{\text {melt }}=0.4 \mathrm{~J}\right.$ ), solid line: PVP with a degree of swelling of 1.27 (absolute amount of water: $1.4 \mathrm{mg}$ ); right hand side: dashed line: $4.3 \mathrm{mg}$ pure water $\left(\Delta H_{\text {melt }}=1.6 \mathrm{~J}\right)$, solid line: PVP with a degree of swelling of 2.11 (absolute amount of water: $4.32 \mathrm{mg}, \Delta H_{\text {melt }}=0.7 \mathrm{~J}$ ); note different scales on y-axes

A series of DSC measurements with various degrees of swelling of the PVP coating were then carried out (Fig. 8). Different crosslink densities were generated by varying the irradiation time. A longer irradiation corresponds to a higher crosslink density (see also Fig. 13). The experiment demonstrated that, indeed, at a degree of swelling of about 1.7 and higher, part of the absorbed water crystallized upon cooling and consequently melted upon heating. This process was basically independent of crosslink density. This can be explained by the fact that the number of pyrrolidone moieties does not change with varying crosslink density. Nevertheless, the crosslink density affects the antiicing effect of the coating, since it determines the equilibrium degree of swelling, which decreases with an increasing crosslink density. Thus, a higher equilibrium degree of swelling results in a longer-lasting antiicing effect.

The enthalpy of fusion of the swollen samples that showed a melting peak in the DSC measurements is plotted versus the absolute amount of absorbed water in Fig. 9 (filled circles). The results are compared with the enthalpy of fusion of pure water (open circles). At the same amount of water, the values differ considerably. The absorbed water does not require as much energy for melting as the pure water because part of it is non-freezing water interacting with PVP chains. ${ }^{18-20}$ Thus, even though the amount of water is the same in absolute terms, not all of it crystallizes in its absorbed state, while it is safe to assume that the free water freezes in its entirety when cooled below a certain temperature (in our case: $-18 \pm 7^{\circ} \mathrm{C}$ ). From a degree of swelling of $q_{\mathrm{w}} \approx 1.7$ upward, at least part of the absorbed water is no longer bound strongly enough to the hydrophilic PVP to prevent it from freezing and it may therefore form crystallites that macroscopically result in an opaque coating. Hence, depending on

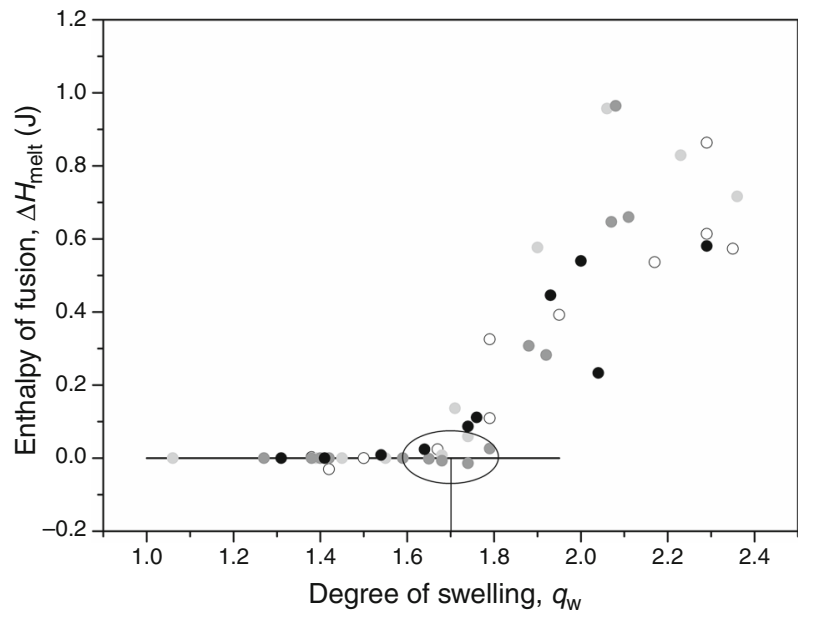

Fig. 8: Plot of the enthalpy of fusion determined by DSC measurements against the degree of swelling of the PVP coating; to vary the crosslink density different irradiation times were used; open circles: $1.5 \mathrm{~min}$, light gray circles: $3 \mathrm{~min}$, dark gray circles: $6 \mathrm{~min}$, black circles: $12 \mathrm{~min}$; at a degree of swelling of $q_{w} \approx 1.7$ the absorbed water starts to crystallize, as indicated by positive values of the enthalpy of fusion, crosslink density has no influence

different parameters, there is a limit to the degree of swelling above which the water absorbed in the coating will start to freeze and possibly lead to opacity. This limit is most probably lower than the equilibrium degree of swelling.

The samples with a lower degree of swelling that did not exhibit crystallization showed the glass transition step of PVP in the DSC curves. It can be seen that not only the properties of the absorbed water are influenced by the interactions with the polymer. The glass transition temperature of PVP is significantly reduced 
from about $180^{\circ} \mathrm{C}$ (dry PVP) to as low as $-40^{\circ} \mathrm{C}$ at $q_{\mathrm{w}} \approx 1.8$ with water acting as a plasticizer. ${ }^{33}$ At even higher degrees of swelling, the glass transition step was superimposed by the melting peak of the absorbed water.

\section{Influence of coating thickness on anti-fog performance under icing conditions occurring in practice}

An important question for the application of the coating in freezers is how the values that were measured before relate to situations that occur in practice. It is necessary to know what degrees of swelling are relevant in the everyday use of the coating in a freezer that is opened once in a while at varying humidities and temperatures. As mentioned above, at a degree of swelling of approximately $q_{\mathrm{w}} \approx 1.7$, crystals are observed in the DSC measurements. This means that light should be scattered by the emerging crystals, leading to an opaque coating.

To determine whether these degrees of swelling are usually exceeded in everyday use, an experiment was carried out with varying coating thicknesses. The samples were placed in a freezer for half an hour and then taken out for $30 \mathrm{~s}$ and weighed. The air humidity was $40 \%$ rh at about $22^{\circ} \mathrm{C}$. This was carried out four times. A fifth measurement was taken at approximately $89 \%$ rh and $25^{\circ} \mathrm{C}$.

The results are illustrated in Fig. 10. The range of degrees of swelling in this experiment was approximately $1.5 \leq q_{\mathrm{w}} \leq 3$. The degree of swelling decreased with an increasing coating thickness but the

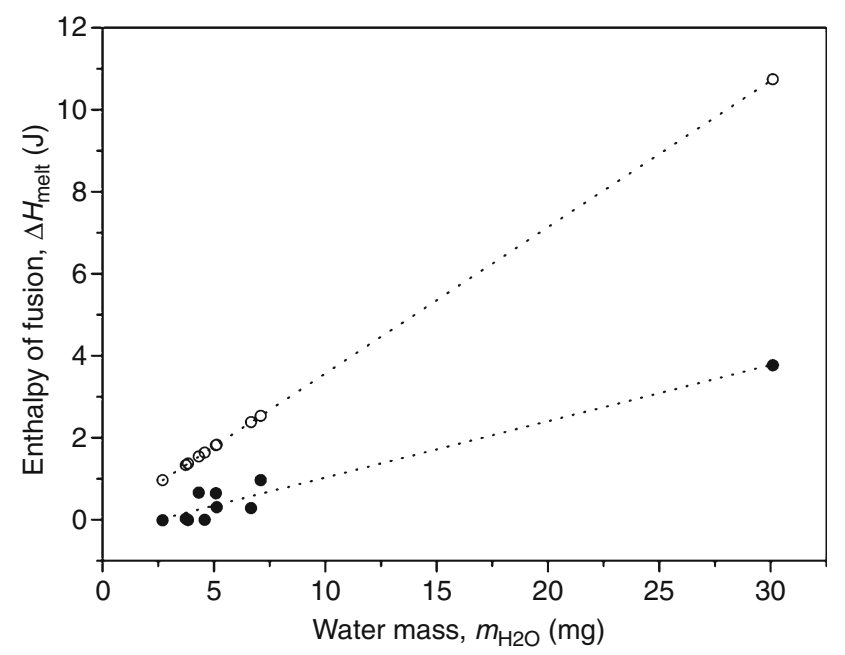

Fig. 9: Plot of the enthalpy of fusion determined by DSC measurements against the amount of water in $\mathrm{mg}$; open circles: pure water, filled circles: water absorbed within PVP; the difference between the pure and the absorbed water is caused by the interactions between water and PVP two different humidities (40\% rh and $89 \%$ rh) showed little difference. The black curve depicts the equilibrium degree of swelling. At a coating thickness of 4-6 $\mu \mathrm{m}$, the degree of swelling becomes lower than the DSC-determined crystallization threshold. Samples with higher thickness should not exhibit opacity at all under the same conditions and samples with lower thickness should fog. It was, however, observed that even at degrees of swelling of $q_{\mathrm{w}}>1.7$, there was no visible opacity. Only at around $q_{\mathrm{w}}=2.5 \pm 0.4$ did the samples start to visibly fog. The ice crystals at $q_{\mathrm{w}}=1.7$ are probably too small or too few in number to visibly scatter light.

As a result, it can be said that the samples that are used for the application of freezer drawers should have a coating thickness of at least $4 \mu \mathrm{m}$, with $6 \mu \mathrm{m}$ or even higher being better, in order to exhibit the best possible anti-fogging abilities. The further away the degree of swelling is from the equilibrium degree of swelling, the lower the risk of the coating becoming opaque.

\section{Water absorption and abrasion testing}

To examine the system further, samples with differing coating thicknesses were used to determine the maximum water absorption and the abrasion resistance. The latter was determined through abrasion testing using the Elcometer 1720. Apart from weight, the samples were examined optically by photography and/or microscopy to detect differences. The water absorption capacity was determined by directly

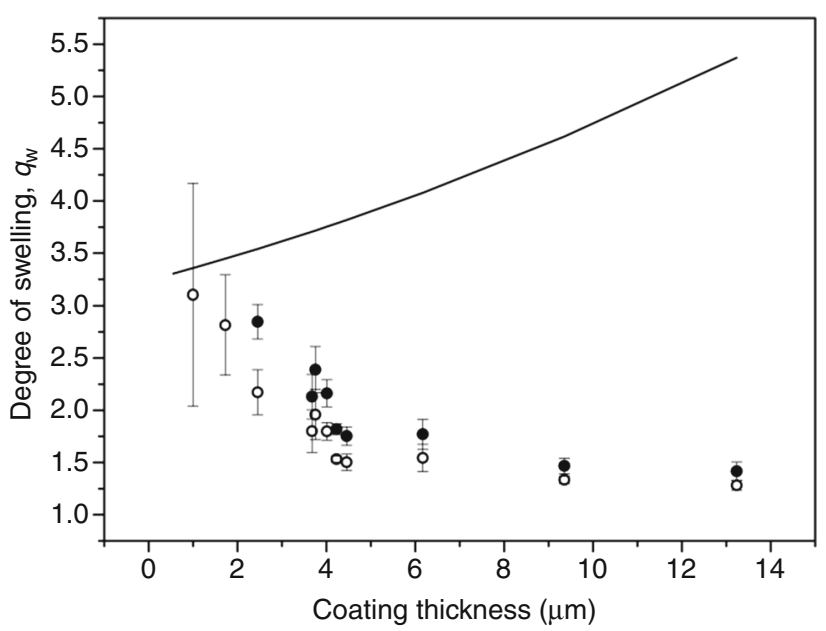

Fig. 10: Dependence of the degree of swelling of samples that were stored in the freezer $\left(-18^{\circ} \mathrm{C}\right)$, then removed and subjected to air moisture, on their coating thickness; open circles: samples subjected to approx. $40 \%$ rh humidity, black circles: samples subjected to approx. $89 \%$ rh humidity, black line: equilibrium degree of swelling at room temperature; $q_{w} \approx 1.7:$ crystallization threshold as determined by DSC measurements (see Fig. 8 ), $q_{w} \approx 2.5 \pm 0.4$ : opacity threshold as detected by the human eye 
immersing the samples in a water bath for $30 \mathrm{~min}$. The results of both experiments showed that the coating thickness has a clear impact on abrasion resistance and water absorption capacity (Fig. 11).

In absolute terms, thicker coatings lose more mass through abrasion than thinner ones, but the extent of abrasion, being the abraded mass in relation to the overall mass of the coating, decays almost exponentially with increasing coating thickness, as can be seen in Fig. 11 on the left hand side. In order to keep abrasion at a low level after scrubbing the coating (e.g., cleaning the drawer), the coating thickness should be at least $4 \mu \mathrm{m}$. Even though the samples with a sufficiently high coating thickness exhibit a relatively low extent of abrasion, the abrasion treatment leaves marks in the form of scratches. The coating is, however, still functional. These scratches mainly occur with the rough side of the sponge, although very thin coatings even show scratches after being treated with the soft side of the sponge (Fig. 12).

After using the rough side of the sponge, the extent of abrasion did not increase very much compared to the soft side. However, from about $4 \mu \mathrm{m}$ upward, the values started to grow again somewhat. This effect can be attributed to the way in which the coatings were made. Multiple dip coating was used to obtain a higher thickness, resulting in much more thickly coated edges. This high thickness allowed the edges to swell a lot more than the rest of the coating, rendering them more susceptible to abrasion because of the softening effect of the swelling. The result can be seen in Fig. 12 on the right hand side. On the upper and lower edge of the
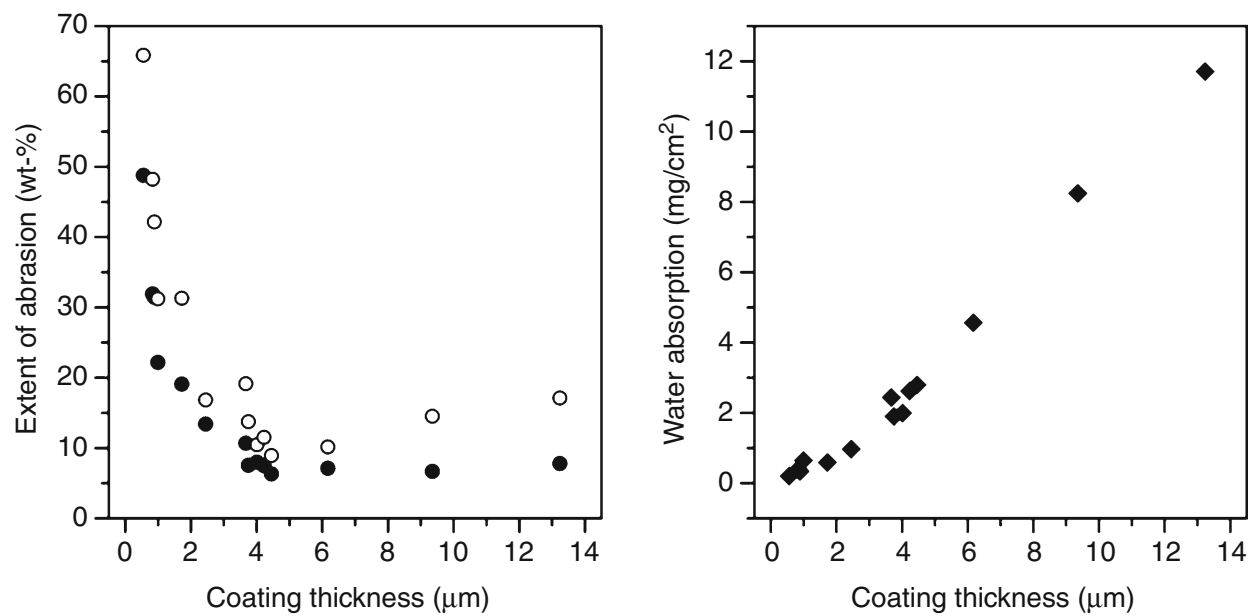

Fig. 11: Dependence of material properties on the coating thickness of the PVP coating; left hand side: dependence of the extent of abrasion in swollen state on the coating thickness, filled circles: soft side of the sponge, open circles: rough side of the sponge; right hand side: dependence of the water absorption on the coating thickness; samples were swollen by immersing them into a water bath for $\mathbf{3 0} \mathrm{min}$
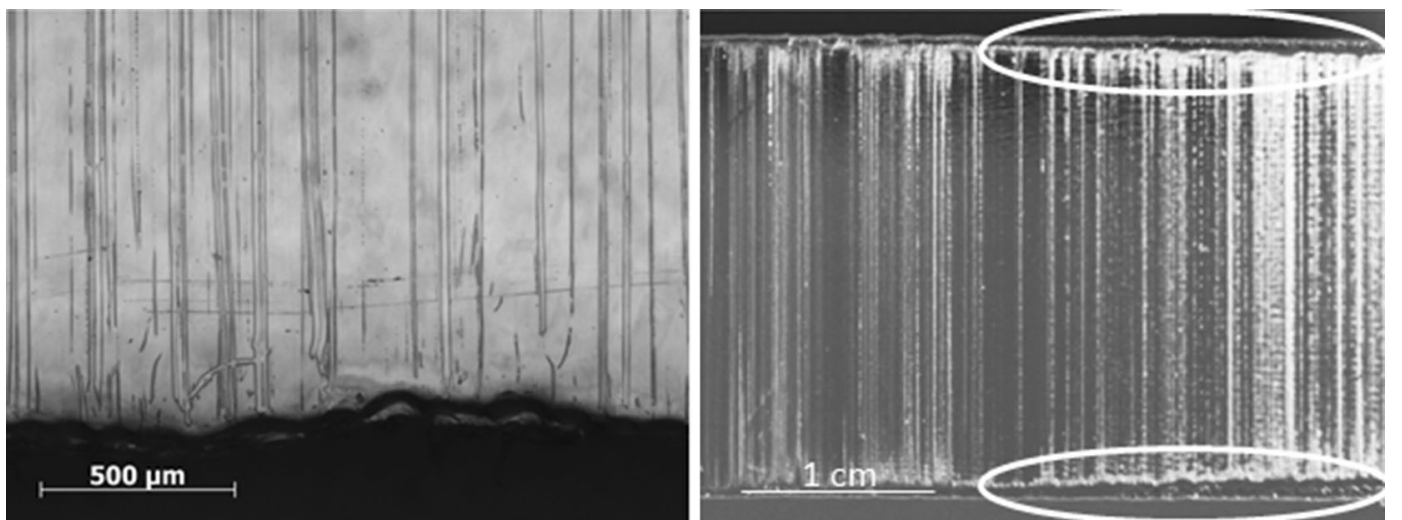

Fig. 12: Illustration of PVP coatings subjected to abrasion testing; left hand side: microscopic image of a relatively thin coating (approx. $1 \mu \mathrm{m}$ ) after abrasion treatment with the soft sponge, right hand side: photograph of a relatively thick coating (approx. $9 \mu \mathrm{m}$ ) after treatment with the rough sponge; circles highlight complete abrasion at the upper and lower edge 
substrate, the coating had rubbed off completely. This would probably not have occurred if the edges had had the same thickness as the inner part of the coating.

Within the observed range, the amount of absorbed water increased linearly with coating thickness (Fig. 11, right hand side). This confirms that the effectiveness of the coating in terms of an anti-fogging effect increases with increasing coating thickness (see also Fig. 10). The higher this is, the longer it takes for the coating to reach the critical degree of swelling where opacity starts to show.

Another factor that has a great impact on the abrasion resistance and water absorption capacity of the coating is irradiation time, which is synonymous with the crosslink density of the PVP network that is created. To examine this influence, a further experiment was carried out.

Theoretically, with increasing crosslink density, the PVP coating should be able to absorb less water, as the equilibrium degree of swelling decreases owing to stronger restraints on the network chains. Different crosslink densities were generated using varying irradiation times. The longer the coating is subjected to UV light, the higher its crosslink density. The typical irradiation time was $6 \mathrm{~min}$. For this experiment, irradiation times ranging from 1 to 6 min were used, reducing the crosslink density that is normally used. The abrasion experiments were always carried out on swollen coatings. Generally, swelling a polymer network results in the loss of mechanical stability; hence, an increasing irradiation time should lead to a lower percentage of abrasion, since the swelling becomes less pronounced and the coating softens less during swelling.

Figure 13 shows that with an increasing irradiation time, the abrasion resistance of the coating in fact increases, which is demonstrated by a decreasing extent of abrasion. Correspondingly, the water absorption capacity decreases. This will have detrimental effects on the anti-fog properties of the coating. Thus, for application on freezer drawers, an optimum has to be defined. The abrasion resistance should be sufficiently high because of potential cleaning of the drawers. However, the reason why the coating is used in the first place is its anti-fog potential, so these two arguments have to be balanced by choosing an appropriate crosslink density. To include the coating thickness into this

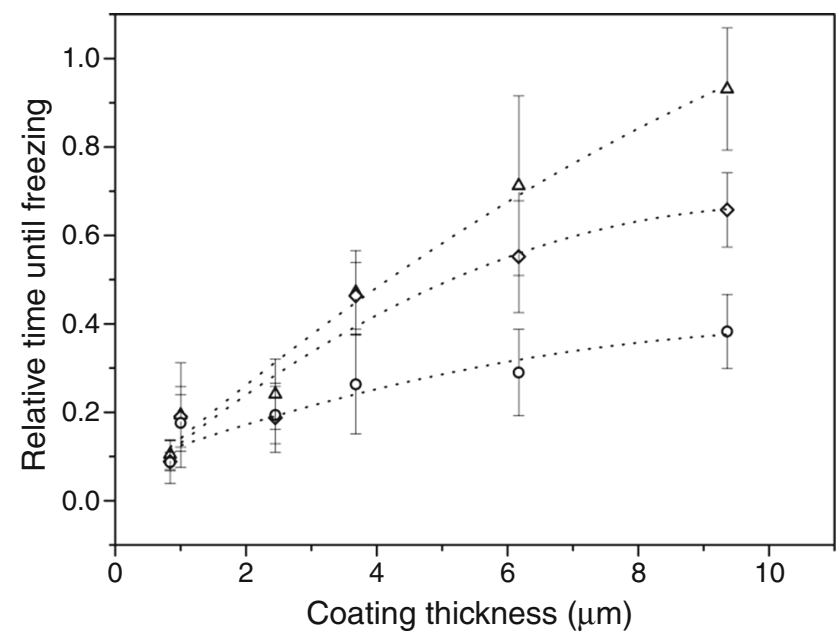

Fig. 14: Results of the experiments in the climate chamber investigating the time it takes until ice crystals are visible on the cooled PVP coating while humid air ( $\approx 50 \% \mathrm{rh})$ is streamed across it at $1 \mathrm{~L} / \mathrm{min}$; relative time until freezing plotted against the coating thickness; triangles: $-20^{\circ} \mathrm{C}$, diamonds: $-30^{\circ} \mathrm{C}$, circles: $-50^{\circ} \mathrm{C}$


Fig. 13: Dependence of material properties on the irradiation time which is proportional to the crosslink density of the PVP coating. Coating thickness of examined samples: $6 \mu \mathrm{m}$; left hand side: dependence of the extent of abrasion on the irradiation time, filled circles: soft side of the sponge, open circles: rough side of the sponge, right hand side: dependence of the water absorption of crosslinked PVP coated on PS on the irradiation time; samples were swollen by immersing them into a water bath for $\mathbf{3 0} \mathrm{min}$ 
discussion, it has to be said that both coating thickness and crosslink density are of comparable importance for the anti-fog behavior. A thicker coating and a lower crosslink density both improve the anti-fog effect by making it last longer. However, coating thickness is limited by UV penetration and crosslink density by mechanical stability.

There are other external factors that influence the anti-fog behavior of the PVP coating, such as the atmospheric humidity, the actual exposure time to the exterior atmosphere, and the temperature in the freezer. This last point was investigated by carrying out water absorption tests in a climate chamber with adjustable temperature. The coated PS plates were placed on a cooling stage within this chamber, set to the correct temperature, and then humid air (50\% rh) at room temperature was streamed across the cold plates. The samples were monitored under a microscope through a window at the top of the chamber. The aim was to detect differences in crystallization behavior of samples with different coating thicknesses and at different temperatures. The relevant parameter was the length of time until ice crystals could be observed. Intuitively, it should take longer for ice crystals to form if the coating thickness is higher, because it takes longer until the critical degree of swelling is reached under the same conditions. Moreover, it should take longer if the temperature is higher, because with increasing temperature the supercooled water comes closer to thermodynamic equilibrium and its inclination to crystallize diminishes.

The outcome of these measurements is presented in Fig. 14. The values have been scaled to a maximum value of one, because the absolute freezing time is irrelevant, as it very much depends on the geometry of the chamber. The important result is the ratio of the values to each other. The graph shows that an increasing coating thickness delays the appearance of ice crystals. The same can be said about an increasing temperature of the samples. Additionally, the values showed higher differentiation if the coating thickness was higher. In order to delay the crystallization, the coating thickness should be as high as possible and the surface temperature should be as warm as possible. The humidity of the atmosphere cannot usually be influenced, but it should be as low as possible.

\section{Conclusion}

Fogging or icing of transparent surfaces is undesirable because it results in opacity, preventing light from passing through the material. When a surface that is cooled to temperatures below the melting point of water comes into contact with a warmer, more humid atmosphere, the application of a hydrophilic crosslinked coating can prevent fogging as well as icing. Such a coating, in our case mainly consisting of the hydrophilic polymer PVP, absorbs the condensing water. Therefore, the formation of superficial droplets that cause fogging is inhibited. Ice crystals are prevented from forming as well, owing to interactions between the water molecules and the hydrophilic polymer.

Our coating consists of crosslinked PVP and is used for transparent freezer drawers made from PS. The coating absorbs water from the atmosphere and keeps it from crystallizing up to a degree of swelling of about 1.7. For higher values, DSC measurements of the swollen coating show more or less broad melting peaks at temperatures lower than $0^{\circ} \mathrm{C}$. However, opacity is not visible to the naked eye up to a degree of swelling of $q_{\mathrm{w}} \approx 2.5 \pm 0.4$.

Water absorption experiments and abrasion tests were carried out. Within the observed range, the following can be said. A higher coating thickness yields a lower extent of abrasion and a higher amount of absorbed water, resulting in a better anti-fogging/icing performance. Fogging and icing cannot be suppressed limitlessly. Depending on the humidity of the surrounding atmosphere and the temperature of sample and atmosphere, a coating under constant or repeated exposure will reach its maximum water capacity at some point, namely its equilibrium degree of swelling. The formation of ice crystals occurs substantially earlier $\left(q_{\mathrm{w}} \approx 1.7\right)$ and the threshold at which these crystals actually cause visible opacity $\left(q_{\mathrm{w}} \approx 2.5 \pm 0.4\right)$ still lies below the equilibrium degree of swelling. It should be mentioned that the coating is capable of regenerating in the freezer if it is not used for a longer period of time (in the range of a few days). The absorbed water and eventually formed ice crystals are able to evaporate/sublimate because of the low relative humidity in the freezer $\left(10-20 \%\right.$ rh at $\left.-18^{\circ} \mathrm{C}\right)$. This works especially well in self-defrosting freezers which are equipped with fans that circulate the air out of the freezer compartment.

Examining the influence of the crosslink density produced conflicting results. With an increasing crosslink density, the abrasion resistance improves but the anti-icing properties deteriorate. Hence, it is necessary to decide which property is more important with respect to the application. The application that we aimed for was freezer drawers. These will probably be cleaned at some point, although not as often as other household objects. A certain abrasion resistance is therefore necessary, meaning that the crosslink density should not be too low. However, to be functional and absorb a sufficient amount of water, it should also not be too high, so the optimum is somewhere in between.

Acknowledgments We gratefully acknowledge the financial support of the Gebert Rüf Stiftung. Karin Dänhardt performed valuable groundwork for this research, for which we want to thank her sincerely.

Open Access This article is distributed under the terms of the Creative Commons Attribution License 
which permits any use, distribution, and reproduction in any medium, provided the original author(s) and the source are credited.

\section{References}

1. Laforte, JL, Allaire, MA, Laflamme, J, "State-of-the-Art on Power Line De-icing." Atmos. Res., 46 (1-2) 143-158 (1998)

2. Hochart, C, Fortin, G, Perron, J, Ilinca, A, "Wind Turbine Performance Under Icing Conditions." Wind Energy, 11 (4) 319-333 (2008)

3. Parent, O, Ilinca, A, "Anti-icing and De-icing Techniques for Wind Turbines: Critical Review." Cold Regions Sci. Technol., 65 (1) 88-96 (2011)

4. Susoff, M, Siegmann, K, Pfaffenroth, C, Hirayama, M, "Evaluation of Icephobic Coatings-Screening of Different Coatings and Influence of Roughness." Appl. Surf. Sci., 282 870-879 (2013)

5. Jensen, KR, Fojan, P, Jensen, RL, Gurevich, L, "Water Condensation: A Multiscale Phenomenon." J. Nanosci. Nanotechnol., 14 (2) 1859-1871 (2014)

6. Howarter, JA, Youngblood, JP, "Self-cleaning and Next Generation Anti-fog Surfaces and Coatings." Macromol. Rapid Commun., 29 (6) 455-466 (2008)

7. Ma, M, Hill, RM, "Superhydrophobic Surfaces." Curr. Opin. Colloid Interface Sci., 11 (4) 193-202 (2006)

8. Sun, Z, Liao, T, Liu, K, Jiang, L, Kim, JH, Dou, SX, "FlyEye Inspired Superhydrophobic Anti-fogging Inorganic Nanostructures." Small, 10 (15) 3001-3006 (2014)

9. Kulinich, SA, Farhadi, S, Nose, K, Du, XW, "Superhydrophobic Surfaces: Are They Really Ice-Repellent?" Langmuir, 27 (1) 25-29 (2011)

10. Davies, J, Nunnerley, CS, Brisley, AC, Sunderland, RF, Edwards, JC, Krüger, P, Knes, R, Paul, AJ, Hibbert, S, "Argon Plasma Treatment of Polystyrene Microtiter Wells. Chemical and Physical Characterisation by Contact Angle, ToF-SIMS, XPS and STM." Colloids Surf. A, 174 (3) 287295 (2000)

11. Guruvenket, S, Rao, GM, Komath, M, Raichur, AM, "Plasma Surface Modification of Polystyrene and Polyethylene." Appl. Surf. Sci., 236 (1-4) 278-284 (2004)

12. Dhayal, M, Alexander, MR, Bradley, JW, "The Surface Chemistry Resulting from Low-pressure Plasma Treatment of Polystyrene: The Effect of Residual Vessel Bound Oxygen." Appl. Surf. Sci., 252 (22) 7957-7963 (2006)

13. Numpud, P, Charinpanitkul, T, Tanthapanichakoon, W, "Photoinduced Hydrophilic Property of $\mathrm{ZnO}$ Thin Films Prepared by Sol-Gel Dip Coating Method." J. Ceram. Soc. Jpn., 116 (1351) 414-417 (2008)

14. Sun, RD, Nakajima, A, Fujishima, A, Watanabe, T, Hashimoto, K, "Photoinduced Surface Wettability Conversion of $\mathrm{ZnO}$ and $\mathrm{TiO}_{2}$ Thin Films." J. Phys. Chem. B, 105 (10) 1984-1990 (2001)

15. Wang, R, Hashimoto, K, Fujishima, A, Chikuni, M, Kojima, E, Kitamura, A, Shimohigoshi, M, Watanabe, T, "Lightinduced Amphiphilic Surfaces." Nature, 388 (6641) 431-432 (1997)
16. Chevallier, P, Turgeon, S, Sarra-Bournet, C, Turcotte, R, Laroche, G, "Characterization of Multilayer Anti-Fog Coatings." ACS Appl. Mater. Interfaces, 3 (3) 750-758 (2011)

17. Lee, H, Alcaraz, ML, Rubner, MF, Cohen, RE, "ZwitterWettability and Antifogging Coatings with Frost-Resisting Capabilities." ACS Nano, 7 (3) 2172-2185 (2013)

18. Hatakeyama, H, Hatakeyama, T, "Interaction Between Water and Hydrophilic Polymers." Thermochim. Acta, 308 (1-2) 3-22 (1998)

19. Ping, ZH, Nguyen, QT, Chen, SM, Zhou, JQ, Ding, YD, "States of Water in Different Hydrophilic Polymers-DSC and FTIR Studies." Polymer, 42 (20) 8461-8467 (2001)

20. Wolfe, J, Bryant, G, Koster, KL, "What Is 'Unfreezable Water', How Unfreezable Is it and How Much Is There?" CryoLetters, 23 (3) 157-166 (2002)

21. Anseth, KS, Bowman, CN, Brannon-Peppas, L, "Mechanical Properties of Hydrogels and their Experimental Determination." Biomaterials, 17 (17) 1647-1657 (1996)

22. Lange, J, Luisier, A, Hult, A, "Influence of Crosslink Density, Glass Transition Temperature and Addition of Pigment and Wax on the Scratch Resistance of an Epoxy Coating." J. Coat. Technol., 69 (872) 77-82 (1997)

23. Tanaka, T, Shao-Tang, S, Hirokawa, Y, Katayama, S, Kucera, J, Hirose, Y, Amiya, T, "Mechanical Instability of Gels at the Phase Transition." Nature, 325 (6107) 796-798 (1987)

24. Guvendiren, M, Yang, S, Burdick, JA, "Swelling-Induced Surface Patterns in Hydrogels with Gradient Crosslinking Density." Adv. Funct. Mater., 19 (19) 3038-3045 (2009)

25. Guvendiren, M, Burdick, JA, Yang, S, "Kinetic Study of Swelling-Induced Surface Pattern Formation and Ordering in Hydrogel Films with Depth-Wise Crosslinking Gradient." Soft Matter, 6 (9) 2044 (2010)

26. Fechine, GJM, Barros, JAG, Catalani, LH, "Poly( $N$-vinyl-2pyrrolidone) Hydrogel Production by Ultraviolet Radiation: New Methodologies to Accelerate Crosslinking." Polymer, 45 (14) 4705-4709 (2004)

27. Ranby, B, Yang, WT, Tretinnikov, O, "Surface Photografting of Polymer Fibers, Films and Sheets." Nucl. Instrum. Methods Phys. Res. B, 151 (1-4) 301-305 (1999)

28. Zhu, X, Lu, P, Chen, W, Dong, J, "Studies of UV Crosslinked Poly( $N$-vinylpyrrolidone) Hydrogels by FTIR, Raman and Solid-State NMR Spectroscopies." Polymer, 51 (14) 3054-3063 (2010)

29. Fouassier, J-P, Photoinitiation, Photopolymerization, and Photocuring: Fundamentals and Applications. Carl Hanser Verlag, Munich (1995)

30. Haenni-Ciunel, K, Findenegg, GH, von Klitzing, R, “Water Contact Angle on Polyelectrolyte-Coated Surfaces: Effects of Film Swelling and Droplet Evaporation." Soft Mater., 5 (2-3) 61-73 (2007)

31. Bourgès-Monnier, C, Shanahan, MER, "Influence of Evaporation on Contact-Angle." Langmuir, 11 (7) 2820-2829 (1995)

32. Rowan, SM, Newton, MI, McHale, G, "Evaporation of Microdroplets and the Wetting of Solid Surfaces." J. Phys. Chem., 99 (35) 13268-13271 (1995)

33. Hamaura, T, Newton, JM, "Interaction between Water and Poly(vinylpyrrolidone) Containing Polyethylene Glycol." $J$. Pharmaceut. Sci., 88 (11) 1228-1233 (1999) 